\title{
Age-Dependent Reference Values of Urinary Porphyrins in Children ${ }^{1}$ )
}

\author{
Elisabeth Irène Minder and Xiaoye Schneider-Yin
}

Zentrallabor and Swiss Porphyrin Reference Laboratory SGKC/IFCC, Stadtspital Triemli, Zürich, Switzerland

Summary: To establish age-dependent reference ranges for the 3 major urinary porphyrins, uroporphyrin, coproporphyrin I and coproporphyrin III, concentrations were measured in random urine specimens from 198 children aged 0.5 to 16 and 18 new-borns by HPLC. All three porphyrins displayed unique age-dependencies. The highest coproporphyrin I concentration was observed in the new-born period, which could be explained by a physiologically under-developed excretion system (via bile and faeces) for this particular porphyrin. Coproporphyrin III excretion reached its highest value in children between ages 1 and 2. Of the three porphyrins, coproporphyrin III concentration showed the closest correlation with the total haem synthesis in childhood. A relatively broad concentration range was found for uroporphyrin in all tested age-groups, the highest mean concentration being in the new-born period. Quantification of each individual urinary porphyrin enables the diagnosis of certain disorders which otherwise cannot be achieved by the total porphyrin determination. As an example of the clinical application of these reference ranges, a case of bronze baby syndrome is discussed.

\section{Introduction}

Porphyrias are inherited disorders of haem biosynthesis, leading to overproduction of haem precursors, the porphyrins. The relatively hydrophilic porphyrins are eliminated in the urine, whereas a minority, especially protoporphyrin and coproporphyrin $\mathrm{I}$, are excreted via bile into the faeces. Most of the porphyrias are not symptomatic before puberty (1). This is perhaps the reason why the reference values for individual urinary porphyrin excretion in children have not been determined so far. However, some rare conditions, such as lead intoxication, bronze baby syndrome, congenital erythropoietic porphyria, hepatoerythropoietic porphyria and eventually long term antiepileptic therapy in children with inherited acute prophyria (acute intermittent porphyria, variegate porphyria or hereditary coproporphyria), can lead to pathological urinary porphyrin excretion in childhood. The reference range of urinary components is usually reported as the amount of substance excreted within a certain period of time, mostly within 24 hours. Alternatively, a urinary component can be expressed in a ratio between its concentration and that of urinary creatinine. Since creatinine is an end product of muscle metabolism, this procedure corrects for interindividual variation of muscle mass, which in turn correlates with body mass. The ratio to creatinine, therefore, is applied especially to reference ranges in children.

There are two important physiological factors that one should take into consideration when evaluating porphy-

\footnotetext{
1) Funding: Hartmann=Müller-Stiftung, Swiss National Science Foundation, Grant No. 32-40544.94
}

rin values. First, the absolute amount of porphyrin excretion is less in children than in adults. Second, rate of haem synthesis in relation to body mass is higher in infants and children than in adults $(2,3)$. With only the adult reference range available, the laboratory results for children are difficult to use for decision making. Thus, the adult reference range expressed as a ratio to creatinine is too low and the adult 24 hour value is too high to be applied directly to children. Nevertheless, a gross estimation based on the adult range can be useful in diagnosing inherited porphyrias where the elevation of porphyrins is usually too massive to be missed. However, questions and doubts are often raised when interpreting results from suspected cases of other disturbances of porphyrin metabolism like lead intoxication, Dubin Johnson syndrome or bronze baby syndrome where the abnormalities are much less significant. This situation urged us to establish a precise age-correlated porphyrin excretion range in children, which could benefit not only the clinical diagnosis of various porphyrias but also the optimisation of laboratory analysis, since the sensitivity and the specificity of any test are strongly dependent upon where the border between normal and pathological values is drawn.

\section{Materials and Methods}

Urine specimens

We analysed 198 random urine samples from children between age 0.5 and 16 which had been sent to the laboratory for amino acid analysis and contained normal quantity of these constituents. Although the study population was not confirmed to be a healthy one, the presence of porphyric individuals was excluded for the following reason. Patients with symptomatic acute porphyrias or lead poisoning excrete increased amounts of 5-aminolaevulinic 
acid in their urine, which would have been detected as an abnormal constituent by amino acid analysis. An additional 18 specimens were collected from infants aged 4 to 10 days who had no hyperbilirubinaemia requiring treatment. Finally, to illustrate the diagnostic relevance of our newly established reference range, the porphyrin concentration was determined in urine samples from a pair of monozygous twins, one of them showing a bronze baby syndrome.

\section{Porphyrin quantification}

Urinary samples were collected without additives and kept at $-20^{\circ} \mathrm{C}$ until analysis. Creatinine concentration (mmol/l) was measured in each sample by the kinetic Jaffe method on a Technicon RA-1000 (Bayer, Germany) before the samples were frozen. One hundred microlitres of internal standard solution (deuteroporphyrin IX-2,4-bisglycol in $3 \mathrm{~mol} / \mathrm{HCl}$, supplied by Porphyrin products, Logan, Utah, USA) was added to $4 \mathrm{ml}$ of urine. The $\mathrm{pH}$ of this mixture was brought to 2.0 with $\mathrm{HCl}(1 \mathrm{~mol} / \mathrm{l})$ before adding 500 $\mu \mathrm{g}$ of talc (purum, pro analysi, 325 mesh; Fluka Chemie Inc., Switzerland). After 1 minute of vortexing, the mixture was centrifuged at $2500 \mathrm{~g}$ for $5 \mathrm{~min}$. The supernatant was discarded and talc with adsorbed porphyrins was suspended in $2 \mathrm{ml} \mathrm{HCl}(0.05 \mathrm{~mol} / \mathrm{l})$ followed by centrifugation. The talc precipitate was once again suspended in $2 \mathrm{ml} \mathrm{HCl}(0.05 \mathrm{~mol} / \mathrm{l})$ and centrifuged. After removal of $\mathrm{HCl}$, porphyrins were eluted from the talc with $5 \mathrm{ml}$ of the elution mixture $(4.9 \mathrm{ml}$ acetone and $0.1 \mathrm{ml} \mathrm{HCl}, 10 \mathrm{~mol} / \mathrm{l})$ by vigorously vortexing. Nine-hundred microlitres of $3 \mathrm{~mol} / 1 \mathrm{HCl}$ was then added to the eluent and acetone was evaporated from the eluent under a reduced pressure. The remaining solution was passed through a 0.2 Micron HPLC filter and injected into a HPLC-column.

Measurement of porphyrins by HPLC has been described previously $(4,5)$. The three individual porphyrins, uroporphyrin, coproporphyrin I and coproporphyrin III, were quantitatively determined $(\mathrm{nmol} / \mathrm{l})$ using a prophyrin acids chromatographic marker kit (Porphyrin products, Logan, Utah, USA) as standards. The ratio of porphyrin concentration to creatinine concentration was then calculated in each sample and expressed as nmol porphyrin/mmol creatinine. As the internal quality control, a normal urine spiked with five different porphyrins (uro-, heptacarboxy-, hexacarboxy-, pentacarboxy-, and coproporphyrin I), each at a concentration of
Tab. 1 Reference values of urinary porphyrins in adults

\begin{tabular}{lll}
\hline Analyte & 24 hour value & Ratio to creatinine \\
\hline Uroporphyrin & $<60 \mathrm{nmol}$ & $<3.9 \mu \mathrm{mol} / \mathrm{mol}$ \\
Coproporphyrin I & $<100 \mathrm{nmol}$ & $<8.4 \mu \mathrm{mol} / \mathrm{mol}$ \\
Coproporphyrin III & $<200 \mathrm{nmol}$ & $<17.8 \mu \mathrm{mol} / \mathrm{mol}$ \\
\hline
\end{tabular}

$50 \mathrm{nmol} / \mathrm{l}$, was included. Reference values' in adults were determined with the same analytical technique in 25 samples collected during 24 hours. The results are given in table 1 .

As stated in Urine specimens, all samples used in this study were not collected originally for porphyrin analysis. Therefore, during sample collection, transport and storage, no special measures had been taken to protect them from light exposure. The samples were left without light-protection for maximally 2 days. To test whether there was any degradation of porphyrins through the sample handling, the following experiment was conducted. Five aliquots from a urine sample were placed in transparent glass test tubes and exposed to day-light for $0,8,24$, and 96 hours, respectively. Their porphyrin concentrations were then analysed by the same procedure as described before.

\section{Statistical analysis}

As an initial step, the concentrations of the three main urinary porphyrins, uroporphyrin, coproporphyrin I and coproporphyrin III, were plotted against the age of the probands (fig. 1a). An agedependency of the urinary porphyrins was noticeable in the resulting scatterplots. For further statistical analysis, the samples were grouped into 12 age-groups. A gliding mean was calculated according to the following procedure: mean and standard deviation were determined from a set that included three adjacent agegroups. The lowest age group was then removed and the next higher age-group was added for the proximate calculation. The new-born group was treated separately and not included in the gliding mean.

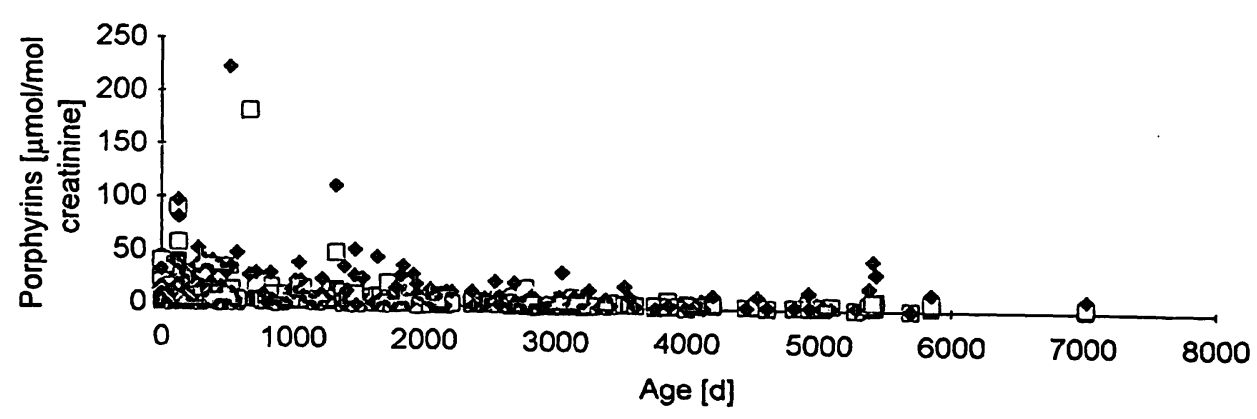

b

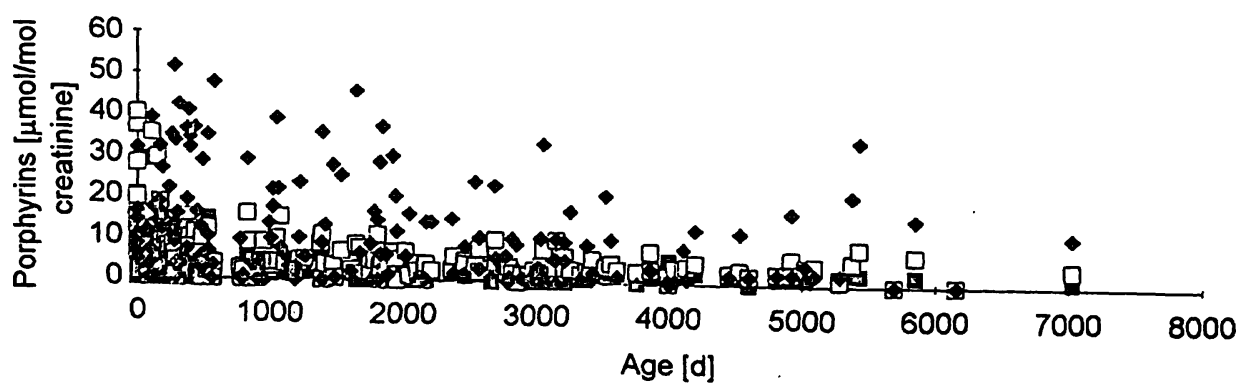

Fig. 1 a) Scatterplot of individual urinary porphyrin excretion versus age from 216 random urinary samples (closed square: uroporphyrin; open square: coproporphyrin I; closed diamond: copro-

b) Scatterplot of individual urinary porphyrins excretion after exclusion of 12 outliers (204 samples remained). porphyrin III). 

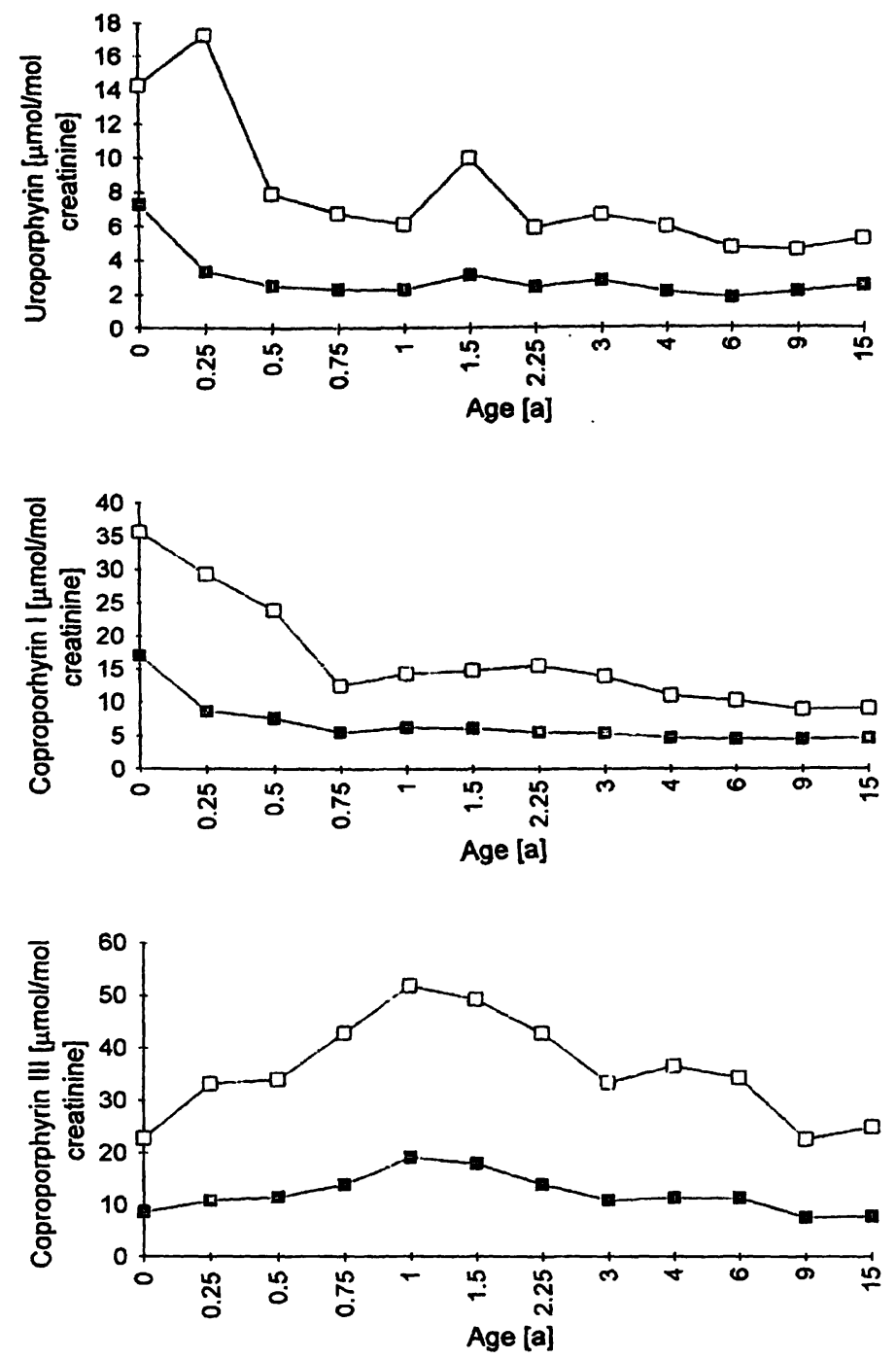

Fig. 2 Age-dependence of the three main urinary porphyrins derived from the raw data (in fig. 1b) after statistical calculation. Closed symbols represent the mean and the open symbols represent the mean plus 2 standard deviations.

Samples exhibiting at least one porphyrin concentration surpassing the mean of their respective age group plus three standard deviations were considered as outliers. Since our study population was not confirmed to be healthy, elimination of outliers from further statistical analysis was appropriate (6). After exclusion of 12 such outliers, the size of the final study group was reduced to 204 samples. The raw data of this corrected study population are depicted in figure $1 \mathrm{~b}$. Once again, a gliding mean and standard deviation for the remaining study population was calculated with the same procedure. The results were plotted separately for each porphyrin (fig. 2).

\section{Results and Discussion}

One potential flaw that might affect the determined reference ranges was a time period (up to 2 days) during which samples were left without proper light-protection. A test was therefore conducted to see whether there was any effect on porphyrin concentrations due to the way these samples were handled. The result showed that there were no concentration changes in uroporphyrin, coproporphyrin I and III during a 96-hour (4 days) period; the coefficients of variation of $3.7 \%$ for uro- porphyrin, $2.8 \%$ for coproporphyrin I and $3.0 \%$ for coproporphyin III $(n=4)$ were within normal analytical performance. In other words, the values that we obtained in the entire study did represent the true concentrations and were not erroneously low.

Each porphyrin shows a distinct age-dependence of the mean and two times the standard deviation which is assigned as upper limit of normal. In the new-born period, coproporphyrin I is the predominant fraction of the excreted coproporphyrins, i. e. $68.4 \pm 12.3 \%$ of the total coproporphyrin. The coproporphyrin I concentration and its fraction in the total coproporphyrin drop sharply during the first half year of life, then gradually approach the adult values at around age 9 . In adults, coproporphyrin I comprises only $28 \pm 15 \%$ of the total coproporphyrin.

Coproporphyrin I is removed from the body mainly through the biliary-faecal route (1). It shares with bilirubin the same transport system for elimination of these substances from hepatocytes into biliary canaliculi (7). Elimination of bilirubin from blood into bile, a possible rate-limiting step in bilirubin excretion, is physiologically immature during the new-born period. This situation is believed to be one of the causes of new-born hyperbilirubinaemia. The same scenario may well be used to explain the elimination of coproporphyrin $I$ in new-borns, i. e. excess coproporphyrin I, although relatively hydrophobic, is forced into the urinary route due to an overloaded biliary-faecal transport system. This assumption is supported by the fact that patients with Dubin Johnson syndrome, an inborn impairment of biliary bilirubin transport, show increases in coproporphyrin I excretion in urine $(8,9)$. The maturation of biliary transport systems could be monitored simply by determination of urinary coproporphyrin excretion and the ratio between isomer I and III.

The maximum excretion of coproporphyrin III is found in children at age one. It decreases slowly thereafter and reaches adult levels in adolescence. Since the isomer III of coproporphyrin (in its reduced form) is an intermediate product of haem metabolism, its concentration in urine is likely to reflect the total haem synthesis rate. The tissues most active in haem synthesis are the bone marrow and the liver. Figure 3 depicts the coproporphyrin III concentration (mean and mean plus 2 standard deviations) together with the relative liver weight from both male and female children (3). The age-dependencies of both properties parallel each other (females age 1.5 to 9: $\mathrm{r}=0.894, \mathrm{n}=13, \mathrm{p}<0.001$; males age 2.5-9: $r=0.85, n=11, p<0.001$ ), except in the newborn period and early infancy when the liver weight is relatively high and the urinary coproporphyrin III concentration is relatively low. Liver cytochromes, as the main haem-containing enzymes in liver, are known to be present only in low concentrations in new-borns (9). 


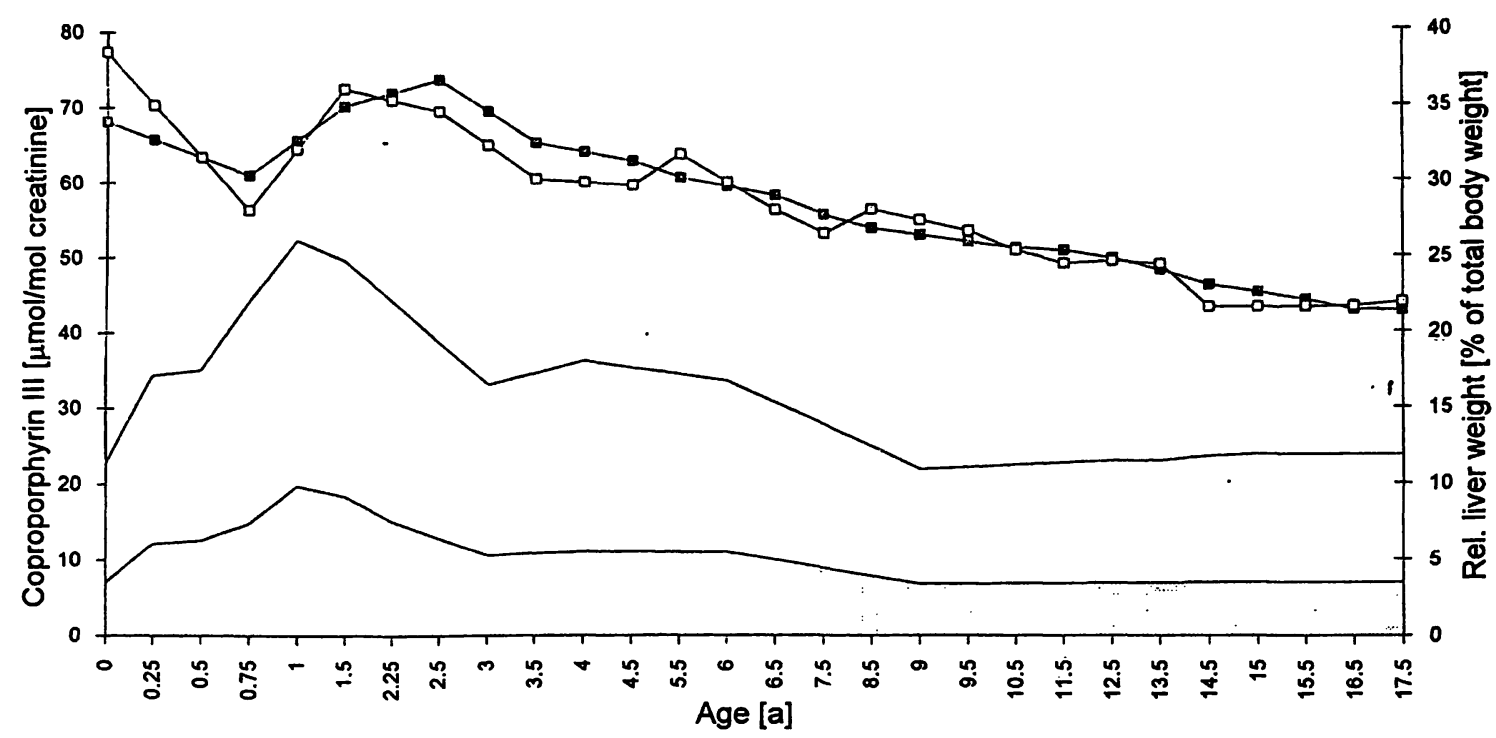

Fig. 3 Age-dependence of urinary coproporphyrin III excretion (mean and mean plus 2 times standard deviation). Values below the mean are depicted by the grey area, values between the mean

This may affect haem synthesis and therefore result in the observed divergence of coproporphyrin III concentration and relative liver weight. The relative weight of bone marrow, another major site of haem synthesis, is supposedly higher in children than in adults. However, exact data are lacking. A direct comparison of relative bone marrow weight with coproporphyrin III excretion is, therefore, impossible.

Uroporphyrin shows some interesting features. Its highest average excretion occurs in the new-born period, when its level is far higher than that in adults. After a sharp decrease to less than $3 \mu \mathrm{mol} / \mathrm{mol}$ creatinine at age 0.5 , the concentration stabilises itself for the rest of childhood. The upper normal limit, defined as the mean plus two standard deviations, however does not parallel the mean value. Rather, it fluctuates by showing two concentration peaks between age 0.25 and 0.5 , and at age 1.5 , respectively. The reasons for this relatively large interindividual variation in urinary uroporphyrin excre- and plus two standard deviations by the white area. The relative liver weight of females is indicated by light-grey symbols, those of males by dark-grey symbols (3).

tion are not known. Table 2 lists the reference values for the three major urinary porphyrins in childhood obtained in this study.

Bloom et al. measured total urinary porphyrin excretion in three age groups, $0-9,9-18$ and $>18$ years old (11). The results provide a limited aid for porphyria diagnosis. Rocchi et al. studied the excretion of coproporphyrin I and III in new-borns between 1 and 10 days old (12). Our reference ranges cover a broader but more subdivided age-spectrum, and therefore enable diagnosis of suspected cases of porphyrias by using reference values for the age in question. In addition, these reference ranges are established from random urine samples that are much easier to collect than 24-hour urine, especially in children.

Urinary porphyrin concentrations determined for a 10 day old baby were: uroporphyrin 28.6 , coproporphyrin I 162 , and coproporphyrin III $58.5 \mu \mathrm{mol} / \mathrm{mol}$ creatinine.

Tab. 2 Urinary porphyrin excretion in childhood

\begin{tabular}{|c|c|c|c|c|c|c|c|}
\hline \multirow[t]{2}{*}{ Age [a] } & \multirow[t]{2}{*}{ Number } & \multicolumn{2}{|c|}{$\begin{array}{l}\text { Uroporphyrin } \\
\text { [ } \mu \mathrm{mol} / \mathrm{mol} \text { creatinine }]\end{array}$} & \multicolumn{2}{|c|}{$\begin{array}{l}\text { Coproporphyrin I } \\
\text { [ } \mu \mathrm{mol} / \mathrm{mol} \text { creatinine] }\end{array}$} & \multicolumn{2}{|c|}{$\begin{array}{l}\text { Coproporphyrin III } \\
\text { [ } \mu \mathrm{mol} / \mathrm{mol} \text { creatinine] }\end{array}$} \\
\hline & & mean & mean $+2 \mathrm{SD}$ & mean & mean $+2 \mathrm{SD}$ & mean & mean $+2 \mathrm{SD}$ \\
\hline 0.00 & 18 & 7.28 & 14.26 & 17.08 & 35.68 & 8.65 & $22.75^{\circ}$ \\
\hline 0.25 & 19 & 3.32 & 17.24 & 8.58 & 29.22 & 10.86 & 33.12 \\
\hline 0.50 & 28 & 2.44 & 7.80 & $\begin{array}{l}0.50 \\
7.49\end{array}$ & 23.80 & 11.26 & 33.78 \\
\hline 0.75 & 24 & 2.20 & 6.66 & 5.31 & 12.22 & 13.57 & 52.59 \\
\hline 1.00 & 22 & 2.13 & 5.96 & 5.99 & 14.02 & 18.82 & 51.47 \\
\hline 1.50 & 22 & 2.92 & 9.77 & 5.77 & 14.38 & 17.54 & 48.79 \\
\hline 2.25 & 17 & 2.19 & 5.67 & 5.10 & 14.96 & 13.31 & 42.24 \\
\hline 3.00 & 25 & 2.53 & 6.39 & 4.84 & 13.33 & 10.24 & 32.67 \\
\hline 4.00 & 27 & 1.83 & 5.65 & 4.08 & 10.32 & 10.63 & 35.73 \\
\hline 6.00 & 44 & 1.49 & 4.40 & 3.78 & 9.45 & 10.47 & $33: 41$ \\
\hline 9.00 & 48 & 1.80 & 4.25 & 3.65 & 8.10 & 6.60 & 21.62 \\
\hline 15.00 & 24 & 2.13 & 4.89 & 3.74 & 8.11 & 6.77 & 23.88 \\
\hline
\end{tabular}


Compared with our newly established reference values for the new-born group, all three porphyrins were elevated significantly which indicated a bronze baby syndrome in this patient. This finding was consistent with the abnormal porphyrin levels determined by other authors in blood from a patient and from an animal model with the same disorder $(13,14)$. There was no disturbance of porphyrin metabolism in the parents of the affected baby, as their urinary, faecal and erythrocytic porphyrins were all normal. The urinary porphyrin concentrations of her monozygous twin sister were within the new-born reference range. These results suggest that bronze baby syndrome is probably a secondary but not an inherited disorder of porphyrin metabolism.

\section{References}

1. Kappas A, Sassa S, Galbraight R, Nordmann Y. The Porphyrias. In: Scriver CR, Beaudet AL. Sly WS, Valle D, editors. The metabolic basis of inherited diseases. 6th ed. New York: MacGraw Hill, 1989:1305-66.

2. MacFarlane RC, Robb-Smith AHT, editors. Functions of the blood. Oxford: Blackwell Scientific Publications, 1961:357.

3. Masse verschiedener Organe in verschiedenen Lebensaltern; Wissenschaftliche Tabellen Geigy, Teilband Somatometrie und Biochemie, 8th ed. Basel: Ciba-Geigy AG, 1982:213.

4. Minder EI, Vuilleumier JP, Vonderschmitt DJ. Prototype application of a robot in the clinical laboratory enabling fully automated quantification of fecal porphyrins. Clin Chem 1992; 38:516-21.

5. Minder EI, Suter B, Vonderschmitt DJ. Wie bewährt sich ein Roboter im klinischen Labor. Labormedizin 1992; 15:118-25.

6. Spichiger UE, Vonderschmitt DJ. A self-consistent set of reference values for 23 clinical chemical analytes. Clin Chem 1989; 35:448-52.

7. Meier PJ. Transport polarity of hepatocytes. Sem Liver Dis 1988; 8:293-307.

8. Koskelo P, Toivonen I, Adlercreutz H. Urinary coproporphyrin isomer distribution in the Dubin-Johnson syndrome. Clin Chem 1967; 13:1006-9.
This is just one example of the clinical relevances of our reference ranges. The age-dependent individual porphyrin reference ranges will enable precise diagnosis of various porphyrias in children.

\section{Acknowledgements}

This study was supported by the Hartmann-Müller Stiftung and the Swiss National Science National Foundation. The skilful technical assistance of Mrs Marianne Brolz and Beatrix Suler is greatly appreciated. We thank Prof. Duc from the neonatology unit of the University Hospital of Zurich and Mr. Holm from the Children's Hospital of Zurich for providing the samples.

9. Konso T, Kuchiba K, Shimizu Y. Metabolic fate of exogenous delta-aminolevulinic acid in Dubin-Johnson syndrome. J Lab Clin Med 1979; 94:421-8.

10. Balistreri WF, Schubert WK. Liver disease in infancy and childhood. In: Schiff L, Schiff ER, editors. Diseases of the liver. 6th ed. Philadelphia: JP Lippincott Company, 1987:1337-41.

11. Bloom K, Zaider E, Mortedge L, Poh-Fitzpatrick M. Urinary porphyrin excretion in normal children and adults. Am J Kidney Dis 1991; 18:483-9.

12. Rocchi E, Balli F, Gibertini P, Trenti T, Pietrangelo A, Cassanelli $\mathrm{M}$, et al. Coproporphyrin excretion in healthy newborn babies. J Pediatr Gastroenterol Nutr 1984, 3:402-7.

13. Rubatelli FF, Jori G, Reddi E. Bronze baby syndrome: a new porphyrin-related disorder. Pediatr Res 1983; 17:327-30.

14. Jori $G$. Reddi $R$, Rubarelli FF. Bronze baby syndrome: an animal model. Pediatr Res 1990; 27:22-5.

Received October 13, 1995/January 30, 1996

Corresponding author: PD Dr. E. Minder, Zentrallabor, Stadtspital Triemli, Birmensdorferstrasse 497, CH-8063 Zurich, Switzerland 
